\title{
Las mujeres y el arte como forma propia de deconstrucción: Un debate implícito
}

Recibido: 4 de abril 2016

Revisado: 14 de mayo 2016

Aprobado: 28 de junio 2016

Patricia Oliva Barboza

Costarricense. Graduada de la Maestría en Violencia de Género por la Universidad de Costa Rica. Facilitadora

en grupos de apoyo: Apropiación del cuerpo a través de la danza.

Practicante de danza

moderna. Investigadora feminista, integrante del Centro de Investigación en Cultura y Desarrollo (CICDE) de la Universidad Estatal a

Distancia de Costa Rica

(UNED).

Correo electrónico: poliva@uned.ac.cr

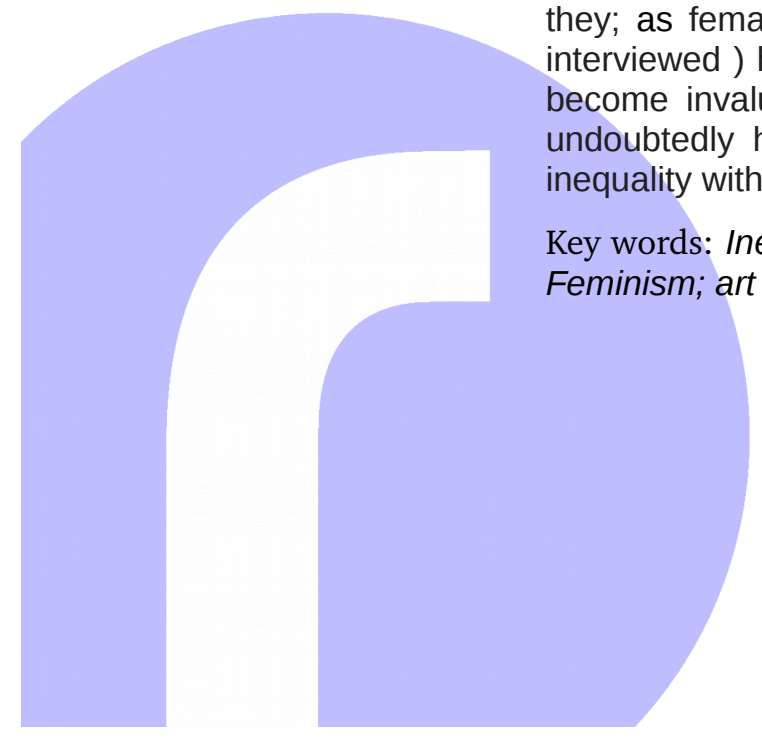

http://investiga.uned.ac.cr/rupturas/

Rev. Rupturas 7(1); Costa Rica; Ene-Jun 2017. ISSN 2215-2466. pp 51-74.
Resumen: Reconocer las distintas formas de deconstrucción que cada mujer redescubre desde su espacio propio; sin que necesariamente se haya asumido en un proceso político o definido como feminista; es el debate que se plantea en este artículo. Tal debate es parte de un proceso investigativo más profundo y cercano a las artistas y resulta en la necesidad de recuperar y compartir las formas propias que; como mujeres artistas costarricenses (que fueron parte del grupo entrevistado) han desarrollado; reinventado y resignificado. Los aportes y valiosísimas contribuciones en el proceso de ruptura las ha transformado. Esto, indudablemente, se suma a las acciones que cuestionan y transgreden la desigualdad dentro del movimiento de las artes escénicas.

Palabras clave: Desigualdad y arte; mujeres artistas; invisibilización de mujeres artistas; arte y feminismo; deconstrucción; mujeres y arte; corporalidades.

\section{Women and Art as a Way of Self deconstruction: An Implicit Debate}

Abstract: The initial debate raised in this article looks to recognize the several ways of deconstruction that every woman re- discovers from her own space; without necessarily being involved in political decisions nor being a selfproclaimed feminist. Also; that being part of a more indepth research process; close to the artists; leads to the need to retrieve and share the ways which they; as female Costa Rican artists ( who were part of the group that was interviewed ) have developed; reinvented and redefined and how these have become invaluable contributions to the breaking process. A process which undoubtedly helps and adds to the actions that challenge and transgress inequality within the movement of the performing arts.

Key words: Inequality and art; women artists invisibility; women artists; art and Feminism; art women deconstruction; corporalities. 
Soy mujer, así que vivo lo que toda mujer vive; en mi hábito, eso sí, trato de imponer lo que creo, lo que considero justo. Lucho haciendo

mi trabajo desde mi posición y mi realidad (Ofir León, fundadora e integrante del Grupo Signos, comunicación personal, 20 de octubre

2011).

1. Investigación adscrita al Centro de Investigación en Cultura y Desarrollo (CICDEUNED), realizada del 2009 al 2011, bajo la coordinación de la investigadora principal $\mathrm{M}$. Sc. Roxana Morales.

2. Denominamos "informante clave" a las artistas con gran trayectoria y experiencia en las artes escénicas, quienes brindaron información sobre las mujeres artistas que podrían contactarse. Como "artistas independientes", agrupamos mujeres que, aunque en algún momento es probable que participaran de un proyecto colectivo, han desarrollado de manera independiente su carrera como bailarina o actriz. Por último, como "integrante de grupo", las artistas (la mayoría más jóvenes) que incursionan en las artes escénicas y que forman sus propias agrupaciones. Lo anterior permite disponer de opiniones muy disímiles considerando la diversidad etaria, espacios institucionales, colectivos, así como momentos históricos y contextos distintos a los que han pertenecido.

\section{Introducción}

En el primero de esta serie de artículos: "La discriminación puesta en escena" (Oliva Barboza 2016), publicado en Rupturas vol. 6, núm.1, 2016, se evidencia la percepción que, sobre desigualdad y discriminación, comparten las mujeres artistas; al tiempo que se visibiliza la trayectoria y los aportes de las mujeres en el arte escénico.

En esta ocasión, se toma como base la información recopilada a partir de la misma investigación "Los movimientos socioculturales contemporáneos de mujeres en Costa Rica. Siglo XXI: Un acercamiento a sus realidades en espacios politizados y artísticos" ${ }^{1}$. Sin embargo, este segundo artículo se nutre, además, de otras reflexiones y propone como punto de partida un debate político, que no es para nada nuevo, en relación con la necesidad de cuestionarnos como investigadoras feministas: ¿desde dónde o cómo nos colocamos frente a las otras mujeres? Debate que surge además desde un proceso auto crítico investigativo a partir del contacto y acercamiento con las mujeres artistas que han generado cuestionamientos sobre la definición de lucha y deconstrucción, y que igualmente invita al ejercicio de separarnos de nuestra propia visión de lucha reflexionando sobre la posibilidad de permitirnos recrear abiertamente las propias formas de luchar sin que necesariamente estas sean definidas desde los feminismos.

Por otra parte, quizás convenga preguntarnos: ¿a qué nos referimos cuando nos asumimos y definimos mujeres feministas?, ¿no es justamente para mirar en las otras y reconocer sus propias formas de transgredir?

Partiendo del hecho de que la práctica artística tiene ya su propia lucha política y gracias al análisis logrado a partir de la cercanía y del trabajo con y desde las mujeres artistas, me permito compartir sus formas de deconstrucción; y al mismo tiempo, cuestionar la posible miopía que afecta o podría afectar la valoración de procesos de lucha en otros grupos u organizaciones de mujeres.

En este análisis, se recupera información de entrevistas hechas a mujeres artistas costarricenses como parte de la investigación antes mencionada. Las citas textuales que se comparten serán diferenciadas según tres categorías: informante clave, artista independiente e integrante de grupo. ${ }^{2}$ 
El principal criterio para la selección, atendiendo las recomendaciones de las informantes clave, fue tratar de abarcar los distintos espacios artísticos. Para ello se hizo el esfuerzo por seleccionar artistas representantes de academias, compañías y grupos artísticos que existían al momento de la investigación. De esta manera, las artistas se contactaron a través de sus grupos o de los distintos espacios artísticos, a saber: Taller Nacional de Danza, Conservatorio El Barco, Compañía Nacional de Danza, Academia Danza, Danza Universitaria UCR, Universidad Nacional y grupos independientes.

Por la dinámica de rotación, muy propia de los grupos o espacios artísticos (una artista puede pertenecer a un espectáculo montado por una compañía o grupo en un momento específico; y al mismo tiempo, tener o ser parte de un grupo independiente), son conscientes de la situación que se presenta en muchos de los espacios.

Para diferenciar las citas por participante sin afectar el anonimato se enumeraron: informante clave 1, 2, 3 y 4; artista independiente 1, 2, 3 y 4; e integrante de grupo $1,2,3,4,5$ y 6 . Algunas reseñas o citas que no comprometen a las participantes se mantuvieron con el nombre real.

Como momento reflexivo para el presente debate, es importante señalar el curso Combatividad y resistencia, Arte y feminismo en América Latina. ${ }^{3}$ Cuando la investigadora española en arte y feminismo Irene Ballester nos solicitó analizar la obra de Frida Kahlo, la primera pregunta del grupo de participantes fue la siguiente: ¿era Frida Kahlo feminista? ¿Podríamos considerar a Frida Kahlo como una artista feminista? La investigadora a cargo respondió con otra pregunta: ¿y para analizar su obra, es relevante reafirmar si Frida fue o no feminista, no es suficiente con su obra? Si estamos analizando su obra y su proceso como artista, ¿no debería ser suficiente?

3. El Curso Virtual Combatividad y Resistencia, Arte y Feminismo en América Latina. Se desarrolló en modalidad en línea, del 11 noviembre de 2013 al 25 febrero de 2014. Este fue organizado por la Asociación Otro Tiempo-Feminicidio.net y coordinado por la investigadora e historiadora de arte: Irene Ballester.

Cuando nos sentimos tentadas a cuestionarnos qué tanto se definen las artistas como feministas, nos dimos cuenta si sería conveniente repensar si esto tiene relevancia o si es parte de nuestra ceguera, cuando finalmente lo que nos interesa es su aporte artístico.

La artista Sophie Krasser (2009) no lo pudo haber expresado mejor en su artículo: "El cuerpo femenino en la danza". Primeramente, señala que no siempre las coreógrafas reivindican sus obras como feministas y que no necesariamente les ha interesado hacer de sus obras y producciones artísticas un acto político; entonces, me surge la interrogante ¿pero que más político que la resignificación de sus cuerpos? Krasser $(2009,33)$ subraya: "Pienso que las mujeres dejan hablar a su cuerpo y que eso en sí es una práctica política, por otra parte, los mensajes que se divulgan a través de sus producciones podrían considerarse como un discurso transformador", sobre esto se ampliará más adelante.

Volviendo al debate, surge otra pregunta ¿le resta valor a sus obras que ellas como artistas se identifiquen como inmersas en una lucha política? Ante esto conviene, además, reflexionar sobre la definición de lucha que estamos 
manejando y si lo estamos leyendo únicamente desde nuestra propia y única definición.

No pretendo responder todas las preguntas sino intercambiar y mostrar las formas propias de deconstrucción; en esta ocasión, desde el arte escénico. También busco generar inquietudes, teniendo presente la miopía que, en esa búsqueda "terca" por identificar indicios feministas en las historias o en la obras (como en este caso), podría en ocasiones estar afectando la esencia del análisis y el acercamiento hacia otros procesos o grupos de mujeres. Esta ha sido la búsqueda primordial en este proceso investigativo-político y colectivo.

\section{Concepto de deconstrucción}

Para explicar el concepto de deconstrucción, me resulta de gran utilidad hacerlo desde su significado contrario o definición directamente opuesta, que sería: "la construcción", la construcción sociocultural entendida como la imposición de patrones binarios (lo femenino/ y lo masculino) que se manifiesta en detrimento de las mujeres y de las personas sexualmente diversas y que constituye el principio básico sobre el cual se sustenta la teoría y la política feminista.

Partiendo de este concepto de "construcción cultural", toda labor, acción, ruptura o aporte en función de descomponer, desatender, desconfigurar, contrariar o combatir esos formatos sociales culturalmente construidos, de manera a veces tan sutil, es lo que se entiende como deconstrucción. Zambrini y Ladevito $(2009,172)$ precisan que fue hacia finales de la década de 1960 que Jacques Derrida introdujo el término deconstrucción. Detallan que su pensamiento incidió en los más diversos campos del saber: en la filosofía, la crítica literaria y la estética; en los análisis de las instituciones y la reflexión política; entre otros. Además resumen en una frase el principal aporte del término: "El propósito de la tarea de-constructiva consiste en deshacer, desmontar lo que ha sido edificado, pero mediante esta labor no se pretende destruirlo todo sino comprender el modo en que ese 'algo' ha sido construido, articulado, y cuál es el sentido que entraña" (Zambrini y Ladevito 2009, 172).

\section{Desde una nueva conceptualización del cuerpo. De "objeto-musa" a "sujeto-creadora"}

Han sido muchas las formas a través de las cuáles las mujeres artistas, sobre todo las bailarinas y actrices, han contribuido en la reconstrucción y en la transformación de los patrones de feminidad socialmente predeterminados. Quizá la primera y la más relevante sea el vínculo que las artistas, en especial las bailarinas, han logrado con su cuerpo, al encontrar formas muy 
distantes de las impuestas desde el patriarcado que justamente centralizan en el cuerpo de la mujer las bases de la opresión y de la desigualdad.

La cultura como construcción masculina, impone una imagen de la mujer que le impide indagar en sus propios rasgos distintivos, en su identidad. Desde otra perspectiva, se propone crear nuevos significados y re simbolizar las metáforas, para lo cual es necesario encontrar a alguien que no haya participado en la creación de la lógica patriarcal ¿Y quiénes han estado siempre al margen de la misma, quiénes han sido situadas en la frontera de lo racional? Las mujeres, sus sentimientos, sus modos de vida, su cuerpo y el lenguaje que de él emana (Carro 2010, 198).

El cuerpo femenino ha sido utilizado en función de otros, para placer de otros, a partir de figuras como la maternidad impuesta; la sexualidad (pero no una sexualidad para sí); y los patrones de belleza irreales e insanos, todos como mandatos incuestionables. Por lo tanto, se trata de un cuerpo marcado al que se le exige el cumplimiento de estándares estructurados y sumamente dañinos para las mujeres.

Aunque como mujeres las artistas no escapan de la lógica patriarcal, a lo que me referiré más adelante, sí intentan transgredir sustituyendo el significado de un cuerpo objeto (de musa) a un cuerpo sujeto creador y activo. Ballester (2012) así lo resume: "Si el cuerpo femenino ha sido fetichizado por la mirada masculina únicamente como puro objeto del deseo, ahora es presentado como soporte sobre el que hablar de temas antes jamás tratados" (p. 21). Lo que se define como "la toma del cuerpo" es ese acto de resistencia desde las mujeres artistas. Solo cuando logran recuperar el cuerpo como sujeto creador surgen lenguajes corporales femeninos antes impensados.

En el prólogo del libro Creación artística y mujeres. Recuperar la memoria de Marian L. F. Cao (2000) ${ }^{4}$, al que me referiré en varias ocasiones en este artículo, Cristina Segura, doctora en Historia Medieval, señala la valoración corporal que históricamente se les ha adjudicado a las mujeres a partir de sus características físicas. Esto sirve para ubicarnos en ese contexto artístico del cual las mujeres inicialmente fueron parte, pero no como objetos activos de creación:

4. Marian L. F. Cao es profesora de Didáctica de la Expresión Plástica en la Universidad Complutense de Madrid y secretaria académica del Instituto de Investigaciones Feministas de esta misma universidad. Además, coordina a las autoras y a los autores de libro: Creación artística y mujeres. Recuperar la memoria. Madrid, España 2000.
Las mujeres efectivamente han sido objeto para los artistas figurativos, pintores, escritores, escultores, etc.,

pero no significa algo positivo para ellas. A estos artistas, 
masculinos en su gran mayoría, las mujeres les han preocupado sobre todo como objetos bellos, pero la representación de esta belleza entrañaba una trampa, pues esto llevaba a la objetivización de las mujeres y, por otra parte, a insistir en que la principal cualidad que deben poseer es la belleza. Todo ello favorecía la pervivencia del patriarcado (Segura, citado en L. F. Cao 2000, Prólogo).

Siguiendo con la reconceptualización del cuerpo como un acto transgresor, podemos imaginar el significado que esto tuvo para las primeras artistas que se interesaron por la práctica del arte. Estas mujeres que fueron tachadas de irreverentes, por arriesgarse no solo a escapar de su designado espacio privado, sino por la osadía -para aquellas épocas- de atreverse a incursionar nuevas formas de reinventar la presencia de las mujeres y nuevas formas de relacionarse y de reinterpretar activamente transformando su cuerpo en sujeto activo y presente

En el arte corporal de las mujeres, el cuerpo adquiere el valor de la presencia activa, de la posibilidad de unión de lo sensible y lo inteligible, casi como lugar de resistencia política, para la reflexión y resignificación de los signos que excluyen a las mujeres (Márquez 2002, 1).

Nuestro país es un referente. No solo fueron las mujeres quienes iniciaron y promovieron la práctica de la danza y el ballet, sino que además se destaca la labor de Mireya Barboza como la precursora de la danza moderna (práctica que conlleva en sí misma un sentido de rompimiento de lo clásico y una enorme rebeldía para la época). Sobre esto me referiré más adelante.

Retomando a las mujeres artistas que reivindicaron ese concepto de cuerpo sujeto, Popelka (2010), en su artículo Estrategias artísticas femeninas como factores de transformación, nos aporta información sobre las artistas de los años sesenta y setenta que se destacaron en la temática de la autorrepresentación del cuerpo:

Serían (estas artistas) las primeras en criticar, ironizar y subvertir las imágenes de la mujer difundida por la tradición del desnudo femenino. Con sus reflexiones contribuyeron al posicionamiento de la mujer como sujeto activo en la autorepresentación de su cuerpo y no como 
se había venido exponiendo hasta ahora como mero

objeto sexual por parte de los artistas varones (Popelka

2010, 190).

Reitero que la idea no es analizar el arte desde la conceptualización de un arte feminista, sino desde el aporte de las mujeres artistas, de un arte más bien femenino, sin intentar definirlas como feministas. Fueron mujeres las que provocaron y lo son aún, en la actualidad, las mujeres las que provocan estas rupturas a partir del cuerpo. "El arte feminista articula el derecho de las mujeres a representar sus propios cuerpos e identidades sexuales, por medio de una imaginería vaginal, imágenes teatrales y del cuerpo, de representaciones de temas previamente tabúes tales como la menstruación, etc..." (Popelka 2010, 191).

Esas inquietudes por resignificar las corporalidades y "supuestas" funciones del cuerpo femenino las vemos hoy representadas en obras de artistas nacionales, unas con mayor intensidad que otras. No obstante, muchas también utilizan esa "imaginería vaginal" para revertir o subrayar irónicamente el cuerpo objetivizado. Por ejemplo: la obra Vacío, de Roxana Ávila, una obra multisensorial, en la cual desde proceso creativo y montaje hubo participación total de mujeres, representa la construcción de la locura femenina, pero además la subvierte con sátira y drama. Con gran interés en esta obra se profundiza en la sensibilización sobre la violencia que las mujeres vivieron y sufren desde la cosificación y la patologización de sus cuerpos. $^{5}$

5. El grupo costarricense Abya Yala, liderado por Roxana

Artistas como Vicky Cortés, María Amalia Pendones, Selma Solórzano, entre otras, han realizado obras de teatro-danza fuertemente críticas cuestionadoras, utilizando como argumento la expropiación del cuerpo femenino. En fin, las artistas visibilizan un cuerpo que ha sido omitido, borrado, desdibujado, objetivizado en el arte como ocurre en la publicidad, ÁAvila (Codirectora y coreógrafa) es un grupo que fusiona muy variadas disciplinas artísticas, la danza, el teatro, la música, entre otros elementos. con una revaloración del desnudo, a diferencia de la tradición del desnudo femenino que, desde el androcentrismo, ponía énfasis en el exterior del cuerpo.

Pero más allá de los esfuerzos de las artistas desde la performatividad, ser bailarina o actriz conlleva una condición que revierte el significado tradicional del cuerpo femenino, ya que el cuerpo se ubica y se observa desde una expresión algo más liberada, desde lugares distintos a los que se han querido imponer desde el patriarcado. Una de las artistas entrevistada se refirió al significado que tiene para ella la experiencia del movimiento:

El movimiento generó, en mi cuerpo y en mi vida, muchas cosas especiales bonitas, pero también me hizo debatir como mujer. Me encontré con otra mujer que se llama danza, me puso a trabajar de otra manera aclarando 
muchas cosas. Supe que quería seguir moviéndome en un escenario toda la vida (integrante de grupo 1. Comunicación personal, 20 de octubre 2011).

Los aportes de las mujeres artistas: bailarinas, actrices, plásticas, escritoras, entre otras, pero más directamente de quienes practican la danza, el teatro y las fusiones de varias disciplinas, contribuyen en la reconstrucción de la identidad femenina. Esa subversión parece estar intrínseca a la práctica misma, por tratarse de actividades que, desde sus inicios, se han enfrentado a los papeles y tareas que han sido impuestas a las mujeres y que les ha restado el placer natural que el cuerpo les brinda.

Del trabajo de investigación, Desde mi cuerpo. Un modelo para abordar la violencia a través de la danza, Oliva (2008) destaca la sensación de apropiación del cuerpo, cuando se transforma y se recupera a través del placer que se genera con el movimiento y la creación:
la danza ofrece sensaciones impensables para las
mujeres y su cuerpo, tiene en sí misma la labor de deconstrucción a partir de la satisfacción que genera, con sólo conectarse con el movimiento, y más si se comparte con otras mujeres en un ambiente libre $y$ voluntario (Oliva Barboza 2008, 110).

Dos de las artistas entrevistadas se refieren a la sensación y al significado que tiene para ellas ser bailarinas: "La danza se identifica muchísimo con la mujer y la mujer con la danza. Una vez que has experimentado esto, nunca puedes dejar de hacerlo" (artista independiente 2. Comunicación personal, 20 de octubre 2011). Otra de las artistas entrevistadas señala: "No es solo la danza, es la formación artística. Yo, por ejemplo, sería otra persona si no hubiera hecho danza; el estar rodeada de arte te hace ver otra realidad cotidiana" (artista independiente 3. Comunicación personal, 20 de octubre 2011).

De ninguna manera se pretende afirmar que la totalidad de las mujeres artistas o que toda mujer que haya realizado algún tipo de práctica artística sea ajena a las expresiones de desigualdad o exclusión propias del patriarcado, o esté libre de la construcción corporal femenina, según los patrones violentos que han sido impuestos, pero sí sucede que la vivencia del arte escénico, en especial aquel que pasa, utiliza y atraviesa el cuerpo, genera un nuevo lenguaje, con nuevas expresiones, quizá desconocidas para quien no haya tenido la suerte de experimentarlo.

Nada nos libera de la discriminación. De hecho, basta con revisar las luchas y las reivindicaciones que tantas mujeres, feministas o no, seguimos 
impulsando. Nada de esto es distinto ni para una mujer inmersa en un movimiento feminista ni mucho menos por el hecho de ser artistas. Sin embargo, la práctica artística, más aún aquella que implica la práctica corporal, se puede comprender como una herramienta adicional que proporciona poder. En suma, te coloca en una posición distinta que te permite experimentar sensaciones corporales difíciles de percibir en otros espacios.

Aclarado lo anterior, son indudables las posibilidades y los medios de expresión que tienen las artes escénicas. Las mujeres que han podido acercarse a estas disciplinas lo expresan con gran claridad, como el caso de la artista internacional Krasser que hemos venido citando en este artículo, quien se refiere a la danza, incluso, como una especie de espiritualidad y así la define desde su subjetividad; para ella, la danza es un "lenguaje espiritual":

¿La danza sería una forma de espiritualidad, un lenguaje espiritual? ¿Una manera de ignorar "el código de la "desnudez" del cuerpo femenino cuando tomamos la palabra desde nuestro cuerpo sexuado? Sí, con la danza nos encontramos a nosotras mismas, revelamos nuestra creatividad, nuestra expresión; brillamos (Krasser 2009, 36).

Oliva Barboza (2008) destaca la relevancia que tiene la danza como forma de expresión corporal: "Frente al silencio y la negación de nuestras sensaciones, frente al miedo como elemento controlador que minimiza la existencia de la mujer, la danza ofrece una ventana para expresarse y recuperar el concepto correcto del cuerpo". También Krasser $(2009,36)$ se refiere a la danza como medio para la creación de un lenguaje propio: "A través de la lengua de nuestro cuerpo, generamos un deseo de trascendencia originado por ese vivir, trabajar, crear constante frente a los límites de un cuerpo que cambia".

Si de expresión corporal se trata y del uso del cuerpo como forma de expresión, Irene Ballester, en su libro El cuerpo abierto, nos proporciona una cantidad de acciones, performance y participaciones de mujeres artistas, de distintas nacionalidades que han gritado sus experiencias utilizando las formas más extremas de representación corporal. Ballester afirma que el cuerpo de las artistas ha servido como base escénica para expresar sus vivencias femeninas más intensas y dolorosas, vinculadas, por ejemplo, con la sexualidad o la maternidad. "Han convertido su arte y su cuerpo en una plataforma para denunciar los abusos de la violencia de género y el feminicidio. Ellas han utilizado su cuerpo sin limitaciones porque las limitaciones únicamente eran establecidas por el patriarcado" (Ballester 2012, 19). 
Por su parte, Popelka (2010) refiriéndose a los años contemplados entre los sesenta y los setenta, con el auge del performance y la participación de artistas de corte feminista, explica cómo muchas de las obras que realizaron las mujeres en este periodo "tratan, no sólo de destruir las ideologías convencionales, sino de construir una narración alternativa, a saber, un relato de la historia de las mujeres"; se refiere a una única "experiencia femenina" "que les permitirá no sólo reelaborar su propia biografía, sino también transgredir los modelos dominantes impuestos por la cultura patriarcal, dando lugar a una diversidad de prácticas y temáticas artísticas" (Popelka 2010, 191).

Aunque este artículo no pretende profundizar en conceptualizaciones técnicas de las distintas prácticas artísticas, ya que no es el objetivo ni corresponde al campo de conocimiento de la autora, pues dicha información pertenece a los estudios de la Historia del Arte, sí es importante aclarar algunas de las diferencias implícitas que existen entre la danza moderna y la danza clásica o ballet. Estas diferencias son relevantes, pues los orígenes (en ambas prácticas) remiten a contextos sociohistóricos muy particulares que inciden en esa capacidad de liberación y de redefinición del cuerpo que se plantea en este primer punto.

En este artículo, se ha utilizado el término danza" como la práctica de la danza moderna (a lo que me he referido a lo largo del documento). Esta surge justamente por la enorme necesidad de muchos(as) bailarines, hombres y mujeres, por encontrar formas de expresión más libres, lo que no tenía cabida en el ballet clásico. La idea no es detallar cuáles son las diferencias técnicas exactas entre lo clásico y lo moderno, sino compartir algunos de los grandes aportes que se le atribuyen a la danza moderna, a partir de su búsqueda en las rupturas a lo establecido por el ballet clásico, que logró transgredir hacia movimientos más introspectivos y menos estéticos.

En el ballet, las puntas perfectas y lograr un movimiento "lo más limpio técnicamente posible" ha sido su principal logro, mientras que la danza moderna se concentró en transmitir, a través del movimiento, esas otras formas de expresión más liberadoras, aunque para esto también se requiera un esfuerzo físico. Cabe destacar que hoy día existen muchas y muy diversas técnicas de danza moderna y de danza clásica.

Al ejecutar una búsqueda bibliográfica sobre las diferencias básicas entre el ballet clásico y la danza moderna, una vez más se confirma de inmediato la participación activa de las mujeres artistas en la historia y en la transformación de las artes escénicas. Así, ya desde 1900, se menciona la presencia de mujeres, tales como Isadora Duncan y Ruth Saint Denis en América; y Mary Wigman en Europa. En 1930, a Martha Graham; y más reciente en 1945, Cunninghan, entre otras, como parte de las artistas pioneras que incursionaron en la danza moderna. En la siguiente cita tomada del libro Isadora Duncan de Berta Rodríguez (2005) se extrae: 


\begin{abstract}
Acostumbrada como estaba a improvisar y a guiarse solamente por sus propias intuiciones, aquello, al igual que le había ocurrido en la escuela de enseñanza general, le pareció un horror. Desde el primer día se enfrentó al profesor de baile que pretendía inculcarle la necesidad de ponerse en puntas. La enseñanza tradicional del ballet enseña que sostenerse sobre las puntas de los pies es algo bello, pero para Isadora sencillamente era una práctica antinatural, que duda cabe que dolorosa, y por lo tanto fea (Rodríguez 2005, 15).
\end{abstract}

La cita anterior es mucho más que una descripción técnica, ya que permite identificar cómo el aporte de la danza moderna incorpora un discurso político, ya que con la invención de la técnica misma revierte roles, resignificando el protagonismo de las artistas, por ejemplo las famosas "cargadas" que fueron históricamente ejecutadas solo por bailarines hombres, en la danza moderna, las vemos de forma contraria.

En este mismo sentido, Krasser (2009) se refiere a Isadora Duncan, como pionera de la danza moderna y la primera bailarina en romper con los cánones del ballet clásico a principios del siglo XX, y señala:

Rechazó su vocabulario de movimientos fijos y su expresión artificial, despojándose de zapatillas y vestidos encorsetados para bailar bajo una túnica y pies desnudos. Se deshizo de un vestuario que tradicionalmente confinaba a las mujeres en roles subordinados y limitaba la variedad de sus movimientos (Krasser 2009, 26).

El significado de ruptura y la necesidad de expresión, desde el movimiento corporal mismo, se puede resumir señalando; por un lado, que el Ballet Clásico se centraba en la perfección de la línea corporal, en la técnica para una exitosa producción coreográfica, sin enfatizar tanto en lo que se pudiera expresar o transmitir. Por otro lado para la Danza Moderna, la expresión misma es lo más importante más que la línea o forma del cuerpo; esta se convierte en herramienta a través de la cual los/las artistas transforman en arte todo aquello que surja desde sus motivaciones e inquietudes personales.

Según Krasser $(2009,27)$ : "Un nuevo vocabulario se introdujo en las aulas de danza, nuevas palabras como naturaleza y energía emergieron, palabras que 
se utilizaban más en formas artísticas orientales". Desde luego, todo lo anterior ha tenido sus transformaciones y matices, pues depende de las distintas técnicas que han surgido y siguen surgiendo en la danza moderna, en cómo se ha nutrido el ballet o se han fusionado ambas, así como de los estilos propios de cada artista, hombres y mujeres. Además, porque constantemente aparecen nuevas técnicas y lenguajes que hoy probablemente desconocemos.

\section{Recuperación del proceso personal/creativo}

El proceso de transgresión de las artistas no se refleja únicamente en las obras, las que podríamos considerar como un resultado final, sino también en el trasfondo personal que interviene durante los momentos de creación. La idea no es compartir los procesos personales de las artistas con las que he tenido el gusto de intercambiar, muchos de los cuales han sido profundamente transformadores, pero sí enfatizar que lo vivido es lo que, finalmente, ha hecho que las obras aparezcan y se concreten, Popelka (2010, 188) señala:

...implica un aspecto distinto a la concepción masculina del arte, el interés de la artista no es la obra de arte en sí, sino que ésta es el resultado de una vivencia personal. Las mujeres artistas toman conciencia de su historia y deciden hacer de su identidad el tema de arte.

Para introducir este segundo punto sobre el proceso personal y artístico, se destaca que, en el movimiento de las artes escénicas como se ha venido mencionando, la mayoría de las artistas costarricenses trabajan en forma independiente; por lo tanto, no perciben luchas comunes o colectivas, como es el caso de otros movimientos de mujeres feministas o ambientalistas. De hecho, no lo interiorizan como lucha o discurso político, ya que se emprende desde el cuerpo vivido; sobre esto se ha profundizado a lo largo de este artículo, pero se reitera que el proceso en solitario tanto personal (que incide finalmente en la obra) como el creativo son elementos que se suman como un acto político que, desde el arte, realizan las mujeres artistas.

Las artistas procesan sus sensaciones y sus cuestionamientos desde el cuerpo como base de su creación; los expresan como temas vinculados al cuerpo, a sus vivencias personales y a las experiencias que las conectan con otras mujeres cercanas (relación con sus madres, sus hijas, abuelas y otras), entre muchas otras vivencias, que es lo que posteriormente manifiestan a través de las producciones. A partir de sus experiencias más íntimas, por ejemplo, un proceso difícil de maternidad, puede ser para ellas la base sobre la que se impulsó toda una producción. 
Desde el discurso feminista, críticas de arte, performistas, así como artistas plásticas, se han referido mucho al proceso personal de las mujeres artistas. Carro (2010) dedica muchas páginas explicando la vinculación de experiencias personales de la artista Bourgeois con sus obras, las que son ampliamente analizadas en su libro Mujeres de Ojos Rojos. Esta autora profundiza en los procesos personales que intervienen en las obras de Bourgeois así:
Al investigar con nuevos materiales y trasladar a sus obras las experiencias en el ámbito privado, la autobiografía y sus preocupaciones como mujer y como artista, Louise Bourgeois se convertirá en pionera del ataque frontal al modernismos y sus sujetos de representación (Carro 2010, 29).

Son muchas las artistas a quienes se les reconoce ese proceso personal artístico tan cercanamente vinculado a sus obras. Una artista muy conocida, aunque también desde las artes plásticas, es, desde luego, Frida Kahlo, sin duda una de las que mejor reflejó su historia de vida en su obra.

Como dato interesante, en el grupo de teatro-danza costarricense Abya Yala, liderado por Roxana Ávila, se han generado producciones a partir de procesos de creación colectiva formados solo por mujeres. Su directora ha señalado que, tanto para ella como para las chicas del grupo ha sido mucho más que un espacio artístico en el que se gestan obras o montajes, sino que ha llegado a significar un colectivo con espacios para compartir y para crecer como mujeres y como artistas. Roxana se refiere a los procesos que tanto ella como las integrantes han experimentado a lo interno del grupo.

$$
\begin{aligned}
& \text { En el tanto que todas estas mujeres han tenido en el } \\
& \text { transcurso de este último año un proceso de } \\
& \text { transformación personal, porque cada una de ellas es } \\
& \text { una mujer importante en su campo -dan clases, son } \\
& \text { mamás, forman a otros-; en tanto ellas se } \\
& \text { transformaron, yo me transformo también; tomé } \\
& \text { conciencia de cosas y ya estoy haciendo una pequeña } \\
& \text { transformación, no va a cambiar el país; esa es una } \\
& \text { mentira muy grande; y si a eso le sumamos la proyección } \\
& \text { de la obra misma, como el caso de Vacío: Decir lo que no }
\end{aligned}
$$


estaba dicho, ¿qué más? (Roxana Ávila. Comunicación

personal, 20 de octubre 2011).

Menciono, como ejemplo, el proceso creativo de Roxana Ávila que ella misma, con tanta claridad, nos comentó, pero son muchas las artistas costarricenses que incorporan en las obras episodios de sus vivencias personales. En las obras de María Amalia Pendones (bailarina y fundadora de Danzay) o de Selma Solórzano (bailarina y actriz), muy probablemente, pesan sus experiencias vividas fuera del país. Vicky Cortés y Ofir León (dos reconocidas bailarinas), sin duda, imprimieron en sus producciones su sello cargado de vivencias en relación con sus historias de maternidad y de migración. No es extraño escuchar a muchas de las artistas referirse repetidamente al sentimiento de catarsis que siempre les produce el proceso y la obra misma.

\section{La gran contribución de "las pioneras"}

Una de las cosas bonitas que descubrí fue que el teatro y la danza se convertían en herramientas: en manos y brazos con los cuales poder trabajar con mucha gente y eso me lo dieron mis primeras maestras en danza (integrante de grupo 1. Comunicación personal, 20 de octubre 2011).

Sin duda, las primeras artistas que influenciaron en esta búsqueda transgresora frente a la feminidad impuesta y a quienes debemos un gran agradecimiento son las mujeres "pioneras". A ellas, tenemos que premiar por sus aportes y contribuciones, por haber incursionado en las artes, en una época en que la mujer era absolutamente excluida del espacio público con todo lo que esto implicaba, los espacios formativos, espacios laborales y, más aún, espacios artísticos.

Para iniciar la recuperación de esta historia, citamos primero a (Ávila, 2005) quien relata los antecedentes de la participación de mujeres en la danza, en su publicación Imágenes Efímeras dedica un primer apartado que denomina 'Las Pioneras del siglo $X X^{\prime}$. Esta autora, se remonta al siglo pasado, principios de los años treinta, década en la que ya se vislumbra la participación de artistas como: Grace Lindo, Margarita Esquivel y Margarita Bertau. Posterior a estos primeros años, en Costa Rica continuaron las creaciones de academias, 
formadas por alumnas y mujeres seguidoras de Lindo

(Oliva Barboza 2016, 6).

El protagonismo e impacto de "las pioneras" en la vida de muchas artistas es evidente: "Las mujeres han tenido en sus manos las artes, los espacios y han sido transformadoras, mujeres como Mireya Barboza, Helena Gutiérrez, Marcela Aguilar; antes de ellas, Margarita Bertau y Grace Lindo, han transformado el arte en este país" (artista independiente 1. Comunicación personal, 20 de octubre 2011).

La palabra "pionera" se queda corta si no comprendemos lo que significó atreverse a incursionar en la danza moderna; quizá no se llegue a dimensionar el alcance que esto tuvo para las artes escénicas en el pasado y hoy día. Parece sencillo, pero la contribución de estas artistas fue gigante. La danza moderna, aun en espacios internacionales, fue considerada una total rebeldía contra los cánones clásicos del ballet. "Después de varios siglos de danza clásica, actividad que era dominada por los hombres, esas mujeres crearon, escribieron una nueva manera de danzar" (Krasser 2009, 19).

La artista Krasser (2009) se refiere a la creación de la danza moderna en el ámbito internacional, en el siglo XX, y describe: "la danza practicada en lo que llamaré, por falta de mejor palabra, Occidente, hizo un viraje decisivo y tomó una cara nueva: se hizo 'moderna' y ese cambio fue impulsado por mujeres como Isadora Duncan, Martha Graham o Doris Humphrey" (p.19). Considero que bien podemos extrapolar lo naterior a nuestro país, donde fue Mireya Barboza quien incursionó y formó el primer espacio para la práctica de la Danza Moderna: el Taller Nacional de Danza. Según Barboza y Naranjo (s.f., 73),

El Taller Nacional de Danza fue creado en 1980 gracias a la visión, esfuerzo y tesón de Mireya Barboza con el objetivo primordial de formar bailarines y promocionar la danza en Costa Rica, fomentar el folclor nacional, la danza moderna y la formación de promotores para cubrir las necesidades nacionales. Al principio adscrito a la Compañía Nacional de Danza durante los primero tres años, luego consiguió independencia administrativa y académica.

¿Qué implicaciones técnicas y artísticas trajo para las artes escénicas la creación del Taller Nacional de Danza y la práctica de la danza moderna? Desde la conceptualización técnica y la diferenciación de lenguajes corporales, de nuevo Krasser $(2009,26)$ nos aporta: 
De la danza moderna las mujeres han sido las inventoras. Se han convertido en innovadoras coreógrafas y no solo en bailarinas, como han sido principalmente en el ballet. En cierto modo, las creadoras de la danza moderna protestaron contra las formas disciplinarias $y$ el virtuosismo del ballet, trabajando desde sus personas, desde sus cuerpos. Introdujeron nociones de gravedad, de peso y de relación con el suelo, cuestionando las representaciones que el ballet hacía de la mujer y del hombre.

Popelka (2010) también señala cómo las artistas hicieron rupturas "utilizaron distintos códigos expresivos, así como materiales y soportes" dejaron atrás los medios tradicionales de representación, "además tomaron la decisión de abandonar el uso de formas y técnicas artísticas vinculadas a la alta cultura" (p.195). Fueron las pioneras tanto en el movimiento internacional como también sucedió en Costa Rica quienes no solo se atrevieron a invadir el espacio público, esta vez representado en las artes escénicas, sino que además sugirieron nuevos lenguajes que al mismo tiempo fueron innovadores e increíblemente críticos.

\section{El aporte desde el trabajo colectivo de las mujeres artistas}

Continuando con lo mencionado anteriormente sobre el bienestar que genera la danza, este aumenta cuando se practica colectivamente. Ese beneficio que ofrece la colectividad ha sido ampliamente validado a partir del estudio y la creación de los grupos de apoyo de mujeres o grupos llamados de autoayuda. El simple hecho de compartir las realidades o, en este caso, practicar una disciplina en forma colectiva ofrece mayores beneficios que la práctica individual.

Mayor aún son los aportes de la danza, que, como ya se ha mencionado, lleva intrínseca la satisfacción y el placer desde la sensación de apropiación del cuerpo de las mujeres. Sobre este tema se refirió la directora de uno de los grupos de teatro-danza entrevistada, quien compartió la experiencia gratificante que le generó el trabajar con mujeres en una de sus obras: "En Vacío, éramos 12 mujeres, todas distintas, no hay interés por homogeneizar nada, entonces cada una con su idiosincrasia; todas estamos aprendiendo a ser más suaves y envolvernos en esa energía" (Roxana Ávila. Grupo Abya Yala. Comunicación personal, 20 de octubre 2011). 


\section{Desde los aportes en la formación y la docencia}

Siempre les decía que siguieran sus sueños. Todas estas chicas han hecho cosas maravillosas. Yo les decía: 'el tiempo de quedarse en casa atendiendo al marido e hijos quedó atrás (informante clave 1. Comunicación personal, 20 de octurbe 2011).

Si nos referimos a las formas en las que las artistas contribuyen a la reconstrucción identitaria, no podemos obviar los enormes aportes que, en este sentido, han estado haciendo por muchos años y continúan haciendo las artistas que transmiten sus conocimientos, expresiones, técnicas y creatividad.

El trabajo de las profesoras de danza y de teatro, quienes a través de sus clases reproducen también su fuerza creadora y sus creencias hacia las chicas más jóvenes, niñas y niños, es sin duda una función prioritaria en la deconstrucción de mandatos femeninos.

Lo primero que tenemos que hacer es comenzar por trabajar con niñas. En el momento en que comencemos, desde las más jóvenes, tendremos mejores resultados a largo plazo. Ojalá abarcar toda la escolaridad. Mi experiencia desde 1982 está ligada al trabajo con niñas.

Creo que he influenciado en otras mujeres porque soy bailarina y soy mamá (artista independiente 3 . Comunicación personal, 20 de octubre 2011).

El trabajo oculto, pero intenso de muchas artistas no ha sido evidenciado como se debería, muchas han aportado desde la transmisión de conocimientos, con técnicas innovadoras y participativas en el trabajo directo con niños y niñas. Las artistas costarricenses fueron las primeras maestras, aunque no se haya reconocido su trayectoria en la creación de técnicas y lenguajes (ver artículo 1: "La Discriminación puesta en escena" de Oliva Barboza 2016).

Históricamente y en la actualidad, la formación de niñas, niños y jóvenes tiene un peso importante también en las artes, quizás las mujeres que en el pasado y actualmente participan como docentes no han percibido el impacto que podrían tener en las nuevas generaciones.

Es relevante recuperar las iniciativas que mujeres como Ofir León, con el apoyo de Valentina Marenco, realizaron desde el colectivo Signos con los proyectos de teatro-danza infantil; el gran trabajo, como coreógrafa y profesora de niños, niñas y jóvenes, que María Amalia Pendones ha desarrollado desde su propia academia Danzay; o la labor que Zuly Cubero, Isabel Saborío, Alejandra Ortíz y Carolina Hovenga han realizado como 
profesoras de niños, niñas y jóvenes desde el Taller Nacional de Danza (tanto en la sede central como en regiones o comunidades alejadas); y habrá otras muchas bailarinas y artistas mujeres que han replicado su conocimiento y continúan formando niños, niñas y jóvenes en otros espacios artísticos.

Un proyecto innovador en esa misma línea es el que la bailarina y profesora Vanessa de la $O$, junto con su madre la educadora Flor María Jiménez Bolaños, emprenden en el Centro Educativo Shénuk con Cuerpo Expresivo. La artista señala que se trata de "una propuesta metodológica para la educación primaria, que se plantea desde la investigación de la exploración artística y/o corporal para conocer y sensibilizar el cuerpo, con el fin de potencializar la capacidad comunicativa expresiva y creativa de los niños y las niñas".

Dicha propuesta ha sido implementada desde la creación del centro educativo Shénuk que tiene 16 años de funcionar. Según comenta Vanessa de la O: "se ha ido puliendo. Poco a poco se ha tomado lo que ha funcionado, pero la idea del tiempo-espacio del método Montessori más la educación artística ha sido el gran tema que ha estado presente desde el principio" (Vanessa de la O. Comunicación personal, 15 de octubre 2011).

\section{El aporte a través de las representaciones y producciones artísticas}

Sus cuerpos son primordiales: son el emisor, el receptor y el mensaje, y no dejan indiferente a ningún espectador, al adoptar una actitud de compromiso social que convierte sus trabajos en pequeños actos de resistencia y denuncia ante el falocentrismo

(Ballester 2012, 23).

La recuperación de ese "cuerpo sujeto" en la práctica artística implica para las mujeres la capacidad y la necesidad de crear. Sin sujeto creador, en este caso creadora, no hay creación posible: "la creación necesita de las características del sujeto para hacerse efectiva" (L.F.Cao 2000, 15). La toma del cuerpo, la apropiación del cuerpo revierte el significado de cuerpo objeto para transformarse en creación artística. Aunque Marian L.F.Cao se refiere a las artistas feministas, son las mujeres artistas en general quienes reclaman el cuerpo para ellas mismas

...mostrándose como productoras de significado no como portadora del significado masculino. El cuerpo denostado, sublimado, utilizado y objetualizado por artistas varones y desde una perspectiva patriarcal, vuelve a sus dueñas y 
es fruto de experimentación desde el sujeto inserto en él

(Cao 2000, 42).

La artista, al colocarse como creadora, es dueña de su representación: "La representación re-presenta, re-construye a las personas y acontecimientos de acuerdo con la ideología gusto y costumbres del sujeto creador del objeto representado" (Cao 2000, 29). Es ella, la artista quien decide, tiene el poder de moldear el mensaje oculto o directo a través de su obra, de la creación de sus personajes y de sus guiones, en el caso del teatro.

La búsqueda identitaria (la lucha constante hacia la deconstrucción de estereotipos y mandatos sociales) se genera a través de las propias creaciones; lo que se convierte en un lenguaje masivo que se multiplica en quienes lo observan y se apropian de él. Mandel Katz, $(2010,65)$ define la creación artística como "un proceso por el cual se entabla un diálogo con el propio ser, el cual puede considerarse una hipótesis frente al conflicto que plantea el mundo".

La lucha de las artistas por mantenerse en el medio artístico ocurre, entre otras formas, a través de la creación, desde el desarrollo de sus propias muestras, y representando, a partir de sus estilos, todo aquello que deseen representar. Son sus obras, procesos y montajes, el lenguaje perfecto para expresar y para enfrentarse con las estructuras patriarcales que existen en el movimiento artístico. "Otra de las consignas que plantean la performance y la danza posmoderna de mujeres, es la construcción de subjetividades que incluyen la experiencia corporal planteada de forma transgresora para el patriarcado"(Márquez 2002, 139).

Una de las artistas jóvenes entrevistadas se refiere a la persistencia de la creación: "Siento que siendo consecuente, si una sigue en la búsqueda, que además es una búsqueda más fuerte porque no tenés el respaldo que deberías, si nosotras seguimos haciendo coreografías, porque sentimos esa necesidad, serán muchas las manifestaciones femeninas" (integrante de grupo 5. Comunicación personal, 20 de octubre 2011).

Las artistas que participaron de las entrevistas, de una u otra forma, se refirieron a la importancia de la creación, de la creatividad como paso esencial en el crecimiento personal, la reafirmación y autodefinición. Una de ellas señaló: "Dentro de este fenómeno, las mujeres han demostrado tener creatividad nueva y fresca. Es una constante reconstrucción, desde que estoy envuelta en el movimiento" (informante clave 2. Comunicación personal, 20 de octubre 2011).

Definitivamente, las artistas se refieren a la creación o a las representaciones artísticas como la principal herramienta para luchar contra esa construcción de la feminidad basada en mitos patriarcales. A continuación, la opinión de una artista: 
Sí, tanto para uno como creadora no deja de ser una reafirmación personal, cuando hacés cosas de este tipo, expresás cosas que a veces la cultura popular no expresa. La cultura popular sigue objetivizando a la mujer, viéndola como un símbolo sexual y, por más talento que tengas, tenés que enseñar partes de tu cuerpo. Mediante la danza, podés ir rescatando tu propia identidad" (informante clave 3, Comunicación personal, 20 de octubre 2011).

Tal es el caso de grupos de mujeres exintegrantes del Conservatorio el Barco, quienes crean, proponen, desde su propio lenguaje técnico, y así lo expresan a través de sus obras y lo multiplican a través de sus clases. Existen iniciativas importantes que tratan de plasmar la temática femenina en muchas obras de teatro danza aunque no todas se han podido desarrollar, sin percibir, quizás, la trascendencia que estas obras pueden significar para el colectivo femenino.

\section{Reflexiones finales}

A continuación, se comparte una síntesis de cada uno de los aportes o contribuciones que en este artículo hemos llamado formas propias de deconstrucción, para retomar las ideas principales que, finalmente, nutren el debate político que se plantea.

El primer y principal aporte de las mujeres artistas surge por la resignificación del cuerpo, intrínseco a la práctica de actividades artísticas, que proveen sensaciones corporales opuestas a las que dictan los mandatos sociales de feminidad. Para las mujeres artistas, el cuerpo femenino se resignifica de una manera única y deja de ser un cuerpo sexuado, cosificado y expropiado, se puede comprender como una transición de "cuerpo objeto" a "cuerpo sujeto"

Con esta síntesis de cómo el arte posibilita a las mujeres artistas relacionarse de manera distinta con su cuerpo, es necesario retomar la siguiente aclaración: no se trata de generalizar, separar o situar a las mujeres artistas en un grupo privilegiado, ya que como se ha venido reiterando, no escapan de las expresiones de desigualdad y violencia como hijas del patriarcado también.

En uno de los análisis que realiza Ballester (2012), en El cuerpo abierto, donde destaca: "No es necesario buscar el posicionamiento estéticoproductivo desde la militancia, pero en su obra, el objeto consumido por la mirada falocéntrica se convierte en sujeto denunciante, y ahí entra el análisis 
desde la perspectiva feminista" (p.260). Es importante reiterar que no todas las mujeres que acceden al espacio público, incluyendo las artes, se ven libres de discriminación. Tampoco redescubriendo su cuerpo con las variadas formas y posibilidades, a través del arte, se garantiza una vida libre de violencia.

Como una contribución más de las artes, que hemos titulado "Trabajo colectivo de las mujeres artistas", surge esa posibilidad de compartir sensaciones con otras mujeres que se interesan por ser parte de estos espacios artísticos; a través de la práctica colectiva de la danza y del teatro, se multiplican los beneficios.

De nuevo es necesario subrayar que esta forma de deconstrucción propia del arte permite otras conexiones corporales distintas; por ejemplo, con la maternidad, sea impuesta o no, o con la sexualidad expropiada de las mujeres. La danza le permite al cuerpo generar sensaciones de bienestar y es una forma única de apropiarse del mismo. Muchas de las mujeres entrevistadas compartieron que la experiencia de la danza, en sus vidas y en sus cuerpos, ha significado mucho más que una práctica física; se ha convertido en un medio de expresión, de crecimiento y de autorreconocimiento.

Los aportes en la formación y la docencia evidencian esa preocupación de profesoras y artistas que encuentran en la danza, a través de las clases y de los grupos, una herramienta para fomentar un continuo cuestionamiento de los patrones masculinos y femeninos. Con un especial impacto en las niñas y adolescentes, una de las profesoras señala: "Creo que sí he influenciado. No es lo mismo dar jazz, que dar danza contemporánea buscando generar, en cada una un lenguaje propio" (informante clave 1. Comunicación personal, 20 de octubre 2011).

Otro de los aportes significativos que, además, ha sido mencionado por una mayoría de mujeres entrevistadas, es aquel que se produce a través de la creación, o representaciones artísticas, llámense obras, montajes, puestas en escena, proyectos, performance, entre otros. Es, a través de esas representaciones artísticas, donde el cuerpo se transforma en protagonista de la escena y en donde las artistas sienten la necesidad de expresar todas sus inquietudes y sus cuestionamientos más genuinos.

Siguiendo con el aporte desde las producciones, es mediante sus creaciones que las mujeres artistas transforman las realidades no solo de ellas mismas, sino también de otras mujeres que comparten esos espacios y de la audiencia que asiste e interpreta sus obras. Las mujeres que han incursionado en la creación artística han contribuido en la transformación y construcción de nuevas identidades femeninas. Las mujeres artistas, en especial las bailarinas y actrices, han proyectado a partir de sus creaciones con sus cuerpos mismos (parte vital en la construcción de la escena) nutriendo directamente esa crítica constante frente a la opresión y la desigualdad. 
Una vez expuestas las síntesis de las "formas propias de deconstrucción", desde las mujeres artistas, es momento de retomar el debate inicial que sugiere como principal reflexión política, desprendernos de la idea que existe una sola y única forma de deconstruir, de participar, de ser parte de la lucha feminista, o bien de la lucha contra la desigualdad y la opresión.

Con este debate se propone por otra parte, reflexionar sobre la necesidad de tener que definirla. ¿Es necesario definir la lucha? o bien, ¿Cada mujer es libre para definir sus propios procesos reivindicativos? Lo relevante es lo que relata cada proceso y las formas propias de ruptura que en ellos se inscriben y desarrollan.

Con la intención de identificar los encuentros que puedan existir entre las reflexiones de las mujeres que luchan desde el activismo feminista de aquellas que lo hacen a través del arte, es relevante reconocer que así como para las activistas y teóricas feministas, el proceso personal cotidiano y el despertar de conciencia se va convirtiendo poco a poco en una cuestión política y se va reconociendo e incorporando como lucha en el discurso feminista, pareciera que no es muy distinto para las mujeres artistas, quienes no necesariamente traducen ese proceso a nivel de lucha política, pero sí atraviesan por momentos de interrogación y búsqueda que poco a poco se van transformando, tomando forma para quedar plasmada en una obra que finalmente tiene el valor de trasmitir, comunicar y compartir esa preocupación inicial.

Keller (1985, citado en Blazquez 2008, 114) se refiere a la objetividad estática y subraya que hay una diferencia entre la objetividad "estática" utilizada en las ciencias tradicionales, que básicamente sugiere un "desapego del científico", añado, científica al objeto de estudio, y esa otra objetividad "dinámica" que es la que propone y sostiene la teoría feminista del punto de vista, que no busca el poder sobre los fenómenos o sobre "lo que se estudia" sino que considera la relación entre quien investiga y el fenómeno es decir "lo que se estudia" así como las formas en que los fenómenos mismos son independientes"

Se sugiere entonces, continuar así, desde estas aproximaciones feministas y cito de nuevo a Blazquez (2008, 115): "permitiendo el encuentro de las perspectivas distintas con el fin de hacer explícitos los compromisos de las distintas situaciones particulares y fomentar la pluralidad de perspectivas de sujetos condicionados". Esto debería atravesar la forma real en la que nos acercamos a los estudios de, con y para las mujeres.

Como recomendación desde la práctica feminista y artística, la propuesta es lograr separarnos un poco de nuestra visión/definición feminista para entender las luchas individuales, los tipos de lucha que no necesariamente tienen que ser o definirse feministas. Al fin y al cabo, es toda forma de ruptura la que nos aporta. 


\section{Bibliografía}

Ávila, A., Marta. 2005. Imágenes Efímeras 10 años bailados en Costa Rica. Centro Cultural de España. Costa Rica: Ediciones Perro Azul.

Barboza, Ligia y Carmen Naranjo. (s.f.). Una vida para la danza. Biografía de Mireya Barboza. San José, Costa Rica: Editorial.

Ballester, Irene .2012. El cuerpo abierto. Representaciones extremas de la mujer en el arte contemporáneo. Asturias: Editoriales Trea.

Blazquez, Norma. 2008. El Retorno de las brujas: incorporación, aportaciones y críticas de las mujeres a la ciencia. Colección Debate y reflexión. México: Universidad Nacional Autónoma de Mexico.

Carro, Susana .2010. Mujeres de Ojos Rojos. Del arte feminista al arte femenino. Asturias, España: Ediciones Trea.

Krasser, Sophie. 2009. «El cuerpo femenino en la danza; escritura de mujer». DUODA. Estudis de la Diferència Sexual, 36: 19-39.

Keller Fox, Evelyn. 1985. Reflexions on gender and science. Londres:..Universidad de Yale. New Haven.

L.F Cao, Marian. 2000. La Creación artística: un difícil sustantivo femenino. En Marian L.F.Cao (Coord.) Creación artística y mujeres. Recuperar la memoria. Madrid: Narcea, Ss.Aa. de ediciones.

Márquez, Patricia .2002. «Cuerpo y Arte Corporal en la Posmodernidad: Las Mujeres Visibles». Arte, Individuo y Sociedad, 14: 121-149.

Mandel, K. Claudia. 2010. Mapa del Cuerpo Femenino. Una lectura deconstructiva de creadoras visuales en Costa Rica. ( $1^{\circ}$ ed). Costa Rica: Editorial UCR.

Oliva Barboza Patricia. 2008. Desde mi cuerpo. Un Modelo para abordar la Violencia a través de la danza. (Trabajo Final de Graduación). Maestría en Estudios de Género. CIEM, Universidad de Costa Rica. Costa Rica. 
Oliva Barboza, Patricia. 2016. «La Discriminación puesta en escena». Revista Rupturas, 6(1): 1-27.

Popelka, Roxana. 2010. «Estrategias artísticas feministas como factores de Transformación Social: Un enfoque desde la Sociología de Género». CIC Cuadernos de Información y Comunicación, 15: 187-196.

Rodríguez, Berta. 2005. Isadora Duncan. Colección: Mujeres en la historia. Madrid: Edimat libros S.A.

Segura, Cristina. 2000. Prólogo. En Marian L.F.Cao (Coord.). 2000. Creación artística y mujeres. Recuperar la memoria. Madrid:. Narcea, s.a. de ediciones.

Zambrini, Laura y Paula Ladevito .2009. «Feminismo filosófico y pensamiento post-estructuralista: teorías y reflexiones acerca de las nociones de sujeto e identidad femenina». Sexualidad, Salud y Sociedad. Revista Latinoamericana, 2:162-180. 